\title{
Effects of traditional oriental medicines as anti-cytotoxic agents in radiotherapy (Review)
}

\author{
WANYEON KIM ${ }^{1,2}$, JIHOON KANG ${ }^{3}$, SUNGMIN LEE $^{3}$ and BUHYUN YOUN ${ }^{1,3}$ \\ ${ }^{1}$ Department of Biological Sciences, Pusan National University, Busan 46241; \\ ${ }^{2}$ Department of Biology Education, Korea National University of Education, Cheongju 28173; \\ ${ }^{3}$ Department of Integrated Biological Science, Pusan National University, Busan 46241, Republic of Korea
}

Received January 2, 2016; Accepted February 23, 2017

DOI: $10.3892 / \mathrm{ol} .2017 .6042$

\begin{abstract}
The primary goal of radiotherapy in oncology is to enhance the efficacy of tumor cell death while decreasing damage to surrounding normal cells. Positive therapeutic outcomes may be accomplished by improved targeting, precisely targeting tumor cells or protecting normal cells against radiation-induced damage. The potential for antioxidants to decrease normal tissue damage induced by radiation has been investigated in animal models for a number of decades. In attempts for radioprotection, certain synthetic chemicals are suggested as antioxidants and normal tissue protectors against radiation-induced damage, but they have exhibited limitations in pharmacological application due to undesirable effects and high toxicities at clinical doses. The present review focuses on the radioprotective efficacy of traditional oriental medicines with the advantage of low toxicity at pharmacological doses and how such treatments may influence various harmful effects induced by radiation in vitro and in vivo. In addition, medicinal plants and their active constituents with biological activities that may be associated with alleviation of radiation-induced damage through antioxidant, anti-inflammatory, wound healing and immunostimulatory properties are discussed.
\end{abstract}

Correspondence to: Professor BuHyun Youn, Department of Biological Sciences, Pusan National University, Busandaehak-ro 63beon-gil, Geumjeong, Busan 46241, Republic of Korea E-mail: bhyoun72@pusan.ac.kr

Abbreviations: CAT, catalase; CTA, conditioned taste aversion; GSH, reduced glutathione; GST, glutathione transferase; IL, interleukin; MDA, malondialdehyde; ROS, reactive oxygen species; SOD-1, superoxide dismutase 1 ; TGF- $\beta 1$, transforming growth factor- $\beta 1$; TNF- $\alpha$, tumor necrosis factor- $\alpha$; TOM, traditional oriental medicine

Key words: antioxidant, cancer, natural product, radiotherapy, radioprotector, reactive oxygen species, traditional oriental medicine

\section{Contents}

1. Introduction

2. Side effects of radiotherapy and need for radioprotectors

3. Traditional oriental medicines

4. TOMs as radioprotectors

5. Conclusions

\section{Introduction}

Ionizing radiation is used as a primary treatment for a number of types of cancer. In total, $>40 \%$ of patients with cancer depend on radiotherapy for the treatment of their disease (1). The major goal of radiotherapy in oncology is to enhance the cytotoxic effects on the tumor while minimizing injury to the neighboring normal tissues. In the last several decades, radiotherapeutic technologies have advanced by improvements in engineering and computing, resulting in the development of intensity-modulated radiotherapy, image-guided radiotherapy and stereotactic radiotherapy (1-3).In addition, spatial-localizing techniques and radiation-fractionated therapy have improved the rate of satisfactory therapeutic outcomes by enabling the repair of radiation-induced damage and regeneration of damaged and fresh cells. Positive therapeutic outcomes may be accomplished by the development of selective radioadjuvants, including radiosensitizers and radioprotectors (4-6). In spite of the improvement in radiotherapeutic modalities, surrounding normal tissues are also affected during radiotherapy, with local tissue damage, mucositis and general weakness occurring (7-9). These undesired side effects should be managed and minimized by treatments of adjuvant compounds. Various agents have been proposed owing to their radioprotective mechanisms and therapeutic effects (10-13). However, as numerous chemical compounds exhibit high toxicity, only a limited number have been investigated in clinical trials. Sulfhydryls have been considered the most promising radioprotectors. Among numerous sulfhydryl compounds, only amifostin (WR-2721, Ethyol ${ }^{\circledR}$ ) has been approved by the US Food and Drug Administration for radiotherapeutic treatment of head and neck cancer $(14,15)$. Further potential candidates for radiotherapeutic adjuvants are expected to decrease the harmful effects of radiation on normal cells. 
Previous studies have been conducted to identify traditional oriental medicines (TOMs) that may serve as potent radioprotectors due to their safety and low toxicity, which have been confirmed by empirical testing and their clinical use in Asian countries (16-20). These compounds have been reported to have antioxidant properties, which may neutralize radiation-induced damage, including oxidative stress caused by reactive oxygen species (ROS). TOMs may regulate abnormal redox signaling by acting as proton donors, reducing agents and metal chelators, consequently exhibiting antioxidant activities. TOMs have also been reported to exhibit anti-inflammatory, pro-survival and anti-cytotoxic activities in animal systems, indicating that they have high potential to serve as radioprotectors. The present review attempts to evaluate the roles of TOMs in decreasing the radiological effects and summarizes the results of studies of radiation and medicinal plants, which may enhance the effects of radiotherapy by protecting normal tissues from radiation-induced damage.

\section{Side effects of radiotherapy and need for radioprotectors}

Ionizing radiation generates electrically charged ions and possesses energy to induce ionization. This energy passes through the cells in the tissues, and may destroy cancer cells or induce damage to the genome, resulting in cell death. Cells may be affected by ionizing radiation directly or indirectly (21). The radiation is able to directly damage biological macromolecules leading to protein malfunction, lipid peroxidation and genetic alterations, including mutations, base lesions and DNA strand breaks. The radiation also causes the formation of ROS including $\mathrm{OH}^{*}, \mathrm{H}^{*},{ }^{1} \mathrm{O}_{2}, \mathrm{H}_{3} \mathrm{O}^{+}$and $\mathrm{H}_{2} \mathrm{O}_{2}$ through the interaction with water molecules $(19,22)$. When these ROS interact with biomolecules, secondary free radicals may be produced, leading to cytotoxic events $(23,24)$.

The majority of radiation-induced DNA damage results from short-lived primary free radicals produced by radiation and secondary free radicals produced by the interaction between primary radicals and biomolecules. In addition, ROS may act as signaling molecules to activate various cellular signaling pathways, including pro-inflammatory, pro-survival and pro-apoptotic responses $(22,25,26)$. Exposure of cells to ionizing radiation results in oxidative stress and DNA damage, with subsequent activation of p53 and ataxia telangiectasia mutated involved in damage-response signaling and cell death signaling. In addition, ROS may induce loss of mitochondrial membrane potential, which consequently leads to the release of mitochondrial pro-apoptotic proteins, including cytochrome $c$, second mitochondria-derived activator of caspases and apoptosis-inducing factor $(25,27,28)$. These pro-apoptotic proteins may subsequently translocate into the cytoplasm and the nucleus to activate mitochondria-dependent apoptosis signaling. Radiation-induced inflammation is regarded as a critical side effect.

Various free radicals may stimulate an inflammatory response through the induction of cytokines and chemokines, which generates long-lived free radicals, leading to chronic damage $(26,29)$. Various cytokines including transforming growth factor- $\beta 1$ (TGF- $\beta 1$ ), tumor necrosis factor- $\alpha$ (TNF- $\alpha$ ) and interleukins (e.g. IL-1 $\alpha$, IL-1 $\beta$, IL-6 and IL-12) that are upregulated by radiation exposure cause radiation-induced inflammation in normal tissues. Chronic inflammation occurring as a late effect of radiation is primarily responsible for the induction of fibrosis, which is an irreversible disease (29-31). In this setting, sufficient amounts of antioxidants as radioprotectors may neutralize the toxic effects of these free radicals and protect normal tissues against ROS-induced damage during radiation exposure (Fig. 1). Positive therapeutic outcomes may be accomplished by scavenging ROS in normal tissues and/or increasing the cytotoxic activities of these free radicals in tumors.

\section{Traditional oriental medicines}

TOMs are typically multi-plant formulas that have long been used to treat diseases in Asian countries (32-34). These natural herbal products have developed through practical testing and improvement over thousands of years. Numerous people around the world currently depend on TOMs for improving their quality of life. In addition, investigation of TOMs provides fundamental knowledge essential for modern drug development. However, a major problem associated with TOMs is limited understanding of their underlying molecular mechanisms of action, which has restricted their widespread application to public healthcare. TOM products are frequently used to treat various symptoms without considering their action mechanisms or disease-causing mechanisms. Therefore, numerous researchers have focused on how each TOM acts in a biological system and what signaling pathways are associated with these phytochemicals. Investigations to elucidate the underlying molecular mechanisms of TOMs have led to the establishment of proper medication protocols and development of promising drugs with decreased side effects. A number of medicinal plants utilized for the treatment of a number of ROS-related diseases including rheumatoid arthritis, cancer, aging and other inflammatory diseases have been identified to exhibit antioxidative, anti-inflammatory, antimicrobial and immunostimulatory activities (16-20). These results indicate that plants may include specific compounds that may protect against radiation-mediated damage as well, which is closely associated with ROS-induced damage.

As a number of types of TOM essentially consist of a multi-plant formula, these compounds may exert synergistic effects that single-active ingredients do not. Such multi-formula medicines may potentiate multi-target approaches to treat complex diseases including cancer caused by abnormal signaling pathways associated with a number of key molecules at the same time (35-37). Their functions may result from an isolated single constituent as well as a combinational effect from crosstalk of a number of constituents in the same plant or multiple plant complexes. For synergistic effects, considerable toxicity produced by major active ingredients of a certain plant may be neutralized by other ingredients in the plant without disrupting therapeutic activities. Therefore, the focus has been on the evaluation of radioprotective efficacy from whole extracts of a plant to isolated constituents based on the anti-cytotoxic activity against radiation-induced damage.

\section{TOMs as radioprotectors}

A variety of TOMs have been reported to contain antioxidant phytochemicals and to have the potential to function in a 


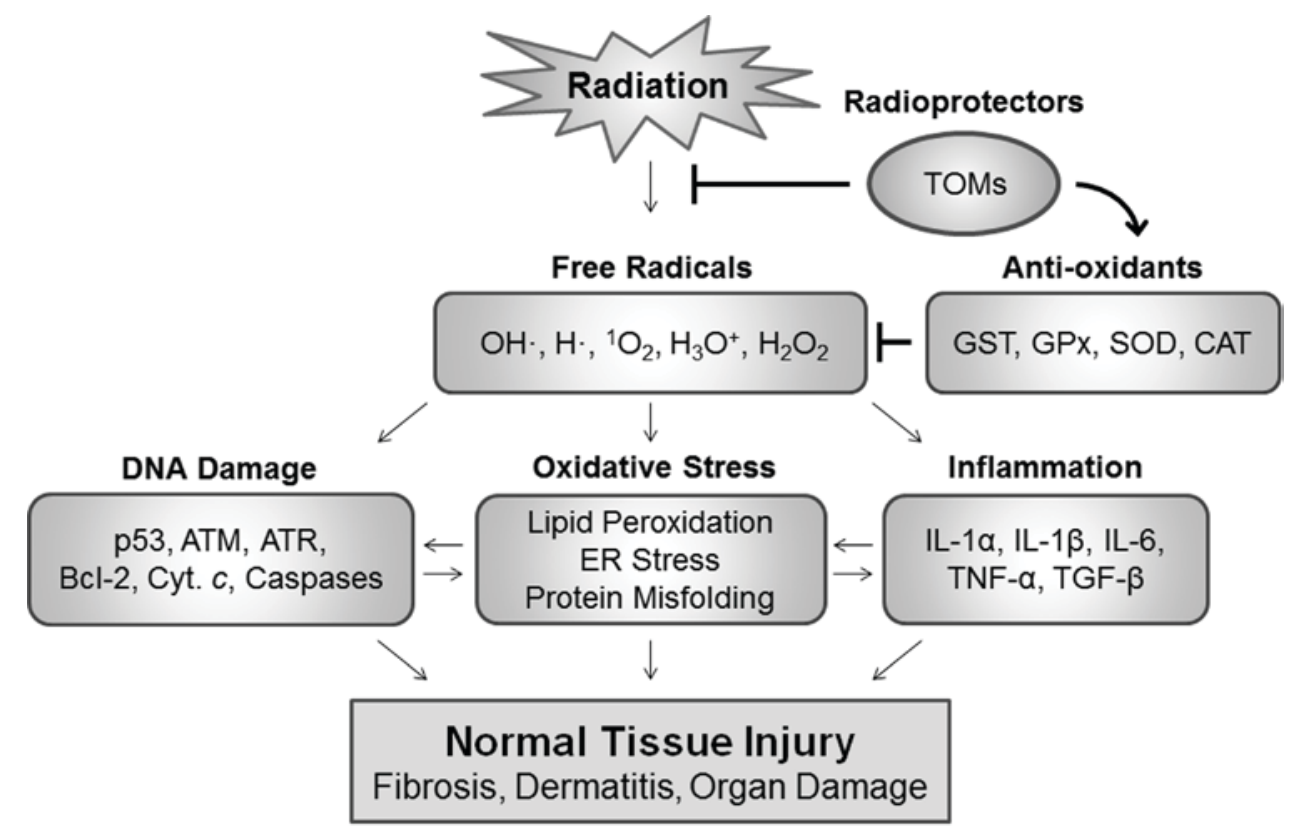

Figure 1. Proposed mechanism for the radioprotective effects of TOMs. Radiation induces formation of free radicals in the cells, which subsequently stimulates DNA damage response, oxidative stress response and inflammation. These events act as major causes for normal tissue injuries including fibrosis, skin dermatitis and organ damage. TOMs exhibiting radioprotective and anti-cytotoxic activities may decrease radiation-induced free radicals through their ROS-scavenging activities and upregulation of endogenous antioxidants, consequently leading to protection of normal tissues against radiation-induced damage. TOM, traditional oriental medicine; GST, glutathione transferase; GPx, glutathione peroxidase; SOD, superoxide dismutase; CAT, catalase; ATM, ataxia telangiectasia mutated; ATR, ataxia telangiectasia- and Rad3-related; Bcl-2, B cell lymphoma 2; Cyt. $c$, cytochrome $c$; ER, endoplasmic reticulum; IL, interleukin; TNF- $\alpha$, tumor necrosis factor $\alpha$; TGF- $\beta$, transforming growth factor $\beta$.

radioprotective role in various systems (16-20). The most appropriate approach to screening candidates as potential radioprotectors is to assess whether an active constituent or a number of compounds with synergistic effects have antioxidative, anti-inflammatory, antimicrobial or immunostimulatory activities. Table I presents a summary of TOMs that exhibit radioprotective activities.

Angelica sinensis. A. sinensis has been used for thousands of years in China to treat a number of symptoms including inflammation, pain, menstrual disorders and amenorrhea $(38,39)$. Pharmacological studies have demonstrated that the compounds purified from A. sinensis root have antioxidant, antitumor, immunomodulatory, neuroprotective and radioprotective activities $(39,40)$. The root extracts of $A$. sinensis serve a radioprotective role through inhibiting radiation-induced lung damage, including pulmonary fibrosis $(41,42)$. These studies have demonstrated that administration of A. sinensis extracts led to the protection of normal lung tissues by decreasing radiation-induced TNF- $\alpha$ and TGF- $\beta 1$ overexpression, which are considered to be responsible for the induction of pulmonary fibrosis. In addition, acidic polysaccharides including $A$. sinensis polysaccharide (ASP) 1 and ASP 3 were identified to be the major constituents of the root extracts, which were reported to alleviate radiological damage and to promote hematopoiesis in bone marrow through the increase in the thymus and spleen index and activation of the phosphoinositide 3-kinase/protein kinase B-mediated survival pathway (43-45). ASP3 may also enhance the expression levels of superoxide dismutase 1 (SOD-1) in liver cells, and inhibit radiation-induced micronuclei formation and apoptosis in liver and bone marrow (46).
Curcuma longa. The Indian spice plant $C$. longa is well-known for containing turmeric in its rhizome, which also contains curcumin. This compound has been used in Ayurvedic medicines for a number of centuries. A variety of studies have demonstrated that the extracts of $C$. long $a$ and curcumin have antioxidant, anti-inflammatory, antiseptic, antitumor and radioprotective activities in a large number of in vitro and in vivo systems (47-51). Additionally, a previous study identified that aqueous extracts of $C$. longa exerted beneficial effects on radioprotection against radiation-induced oxidative stress by modulating antioxidant systems (52). In the present study, administration of $C$. longa extracts to rats prior to and following whole-body treatment with $6.5 \mathrm{~Gy} \gamma$-irradiation resulted in alleviation of transaminase disorders, a decrease in lipid abnormalities, decreased lipid peroxidation, decreased release of inflammatory cytokines including IL- 6 and TNF- $\alpha$, recovery of reduced glutathione (GSH) levels, and increased expression of antioxidant enzymes, including SOD-1 and peroxiredoxin-1, in rat liver. Previous studies have identified that curcumin may serve a radioprotective role in normal cells, although it may enable cancer cells to be sensitized to radiotherapy $(53,54)$. Curcumin exhibits antioxidant potential to improve therapeutic efficacy through the induction of expression of antioxidant genes including SOD-1, catalase (CAT) and glutathione peroxidase, leading to decreased ROS levels and DNA damage (55-57). A study in which curcumin was administered to mice prior to application of $\gamma$-irradiation to the thorax demonstrated that curcumin enhanced the expression levels of heme oxygenase 1 to protect against radiation-induced ROS production, and suppressed acute lung injury, inflammation and pulmonary fibrosis induced by radiation exposure (58). These results were consistent with those of 


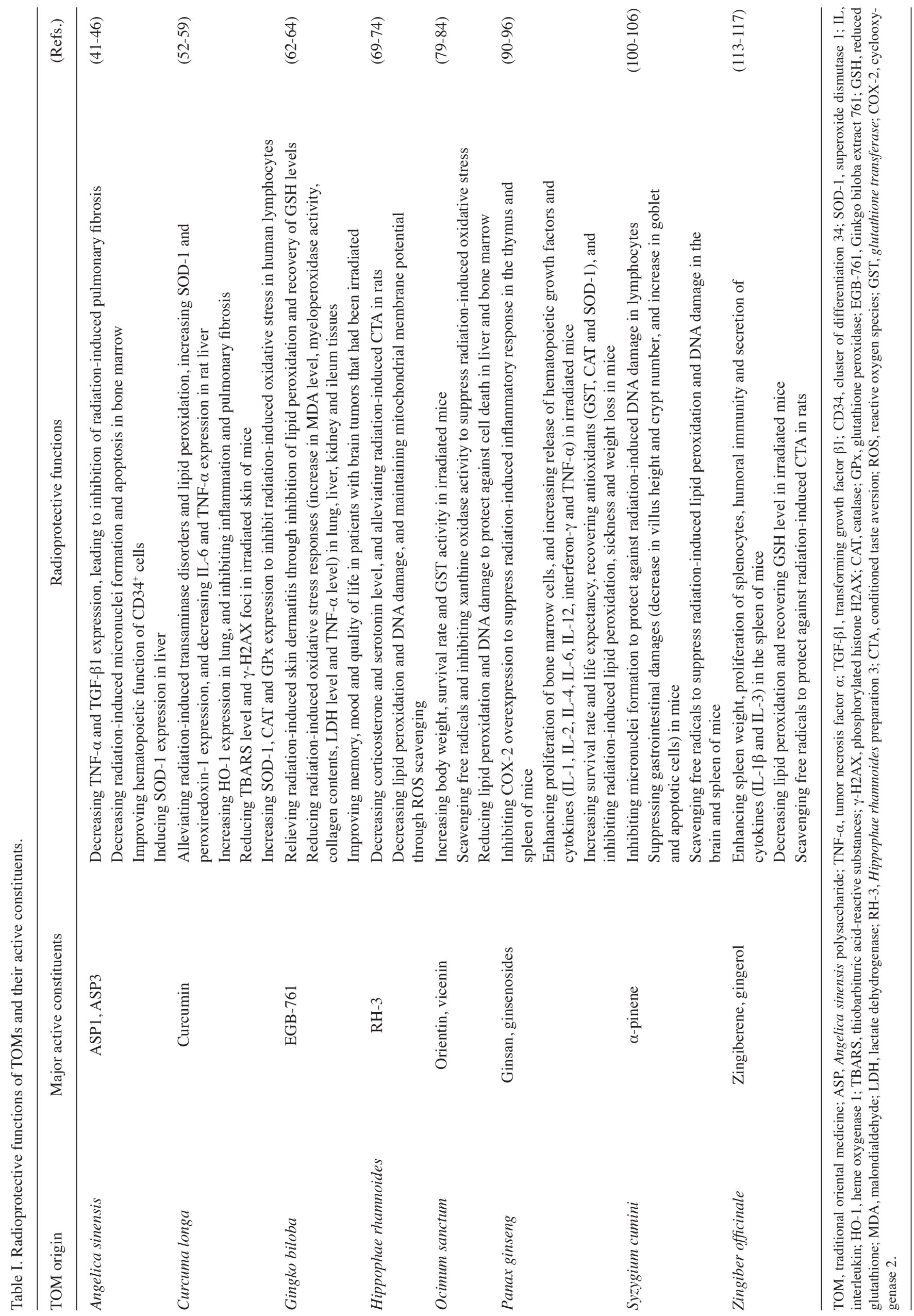


another study that demonstrated that treatment with curcumin combined with radiation exposure to local areas of the skin or the whole body of mice exhibited radioprotective effects via a decrease in thiobarbituric acid-reactive substances and phosphorylated histone $\mathrm{H} 2 \mathrm{AX}$ foci, indicating decreased lipid peroxidation and DNA damage, respectively (59).

Gingko biloba. G. biloba (Cycadaceae), a popular herb in East Asia, has been reported to exhibit beneficial biological activities including antioxidant, anti-inflammatory, anti-aging and cardioprotective properties (60). G. biloba extract 761 (EGB-761) is a mixture of standardized $G$. biloba leaf extracts composed of flavonoids, terpenoids, organic acids and other constituents with antioxidant properties that has been developed and widely utilized as a dietary supplement and herbal therapy (61). The plant contains $~ 300$ compounds including ginkgolides, bilobalide, ascorbic acid, carotenes, quercetin, myricetin, ginkgetin, coumarins, catechins, rhamnetin and tocopherol. The majority of these constituents exhibit radioprotective activities. A previous study identified that EGB-761 serve a protective role in radiation-induced dermatitis (62). As the skin is primarily affected, regardless of the organ targeted by radiotherapy, skin damage including dermatitis may be caused by radiation-induced oxidative stress, lipid peroxidation and redox imbalance. In the present study, administration of EGB-761 to irradiated rats resulted in reduction of radiation-induced malondialdehyde (MDA) levels, an indication of lipid peroxidation, and recovery of GSH levels to normal status, indicating that increased oxidative stress by radiation exposure was significantly suppressed (62). Furthermore, dermatitis caused by radiation was markedly alleviated when EGB-761 was applied. Another study demonstrated that administration of whole-body radiation to Sprague-Dawley rats increased MDA levels, myeloperoxidase activity, collagen contents, lactate dehydrogenase levels and TNF- $\alpha$ levels in lung, liver, kidney and ileum tissues, whereas these oxidative responses were significantly inhibited by administration of G. biloba extracts (63). In addition, the extracts of $G$. biloba resulted in improvement of memory, brain-related symptoms, mood and quality of life in patients with brain tumors that had been irradiated (64). The results of these studies suggest that $G$. biloba extracts serve a protective role against radiation-induced oxidative damage in tissues and organs.

Hippophae rhamnoides. H. rhamnoides has been used in India and Tibet for a number of centuries to treat dyspepsia, wound healing, cardiovascular disorders and hepatic disorders. The plant has been reported to have antioxidant, anti-inflammatory, antimicrobial and immunostimulatory properties (65-67). $H$. rhamnoides berries contain polyphenolic compounds, including rhamnetin, quercetin, and kaempferol, carotenes, vitamins, folic acids and tannins $(68,69)$. These bioactive constituents are responsible for the biological activities that contribute to radioprotection through free radical scavenging. A previous study demonstrated that the alcoholic extracts of $H$. rhamnoides berries resulted in a significant decrease in radiation-induced cytotoxicity via inhibition of radiation-induced ROS in the cytoplasm and mitochondria, as well as through maintenance of the mitochondrial membrane potential (69). The administration of $H$. rhamnoides leaf extracts prior to whole-body radiation in rats partially increased antioxidant systems, whereas it decreased corticosterone levels in plasma and serotonin levels in jejunum and plasma, leading to the prevention of behavioral changes including conditioned taste aversion (CTA) in rats. Since CTA in rodents is regarded as a similar behavior to nausea and vomiting in humans, the extracts could be a promising candidate for the suppression of radiation-induced behavioral effects (70). In addition, the extracts of $H$. rhamnoides have been reported to have the capacity to mitigate lipid peroxidation, genomic DNA damage and mitochondrial DNA damage $(18,71,72)$. These extracts also possess the ability to induce chromatin compaction to protect against radiation-induced DNA strand breaks $(73,74)$.

Ocimum sanctum. O. sanctum, which is also known as Tulsi or Indian holy basil, is a medicinal herb used in Ayurvedic, Greek, Roman, Siddha and Unani treatments. O. sanctum has been utilized for a number of therapeutic treatments including the common cold, vomiting, malarial fever, asthma, bronchitis, hepatic disorders, cardiac disorders and skin diseases $(75,76)$. This medicinal plant reportedly has antioxidative, antibacterial, antifungal, anti-inflammatory, antitumor and immuostimulatory properties. O. sanctum contains a number of constituents including apigenin, caffeic acid, cirsilineol, eugenol, luteolin, orientin, rosmarinic acid, vanillin and vicenin, the majority of which are contained in the leaves and stem $(77,78)$. Studies have been conducted to investigate the radioprotective role of $O$. sanctum since Uma Devi and Ganasoundari (79) first reported its radioprotective properties. It was reported that administration of $O$. sanctum leaf extracts along with radiotherapy resulted in increased body weight, survival rate and glutathione transferase (GST) activity in mouse models with reduced chromosomal damage and tumor volume of melanoma (80). In addition, polysaccharides isolated from $O$. sanctum were reported to prevent lipid peroxidation and DNA damage against oxidative stress induced by $\gamma$-radiation through scavenging free radicals and inhibiting xanthine oxidase activity (81). Among a number of constituents, the flavonoids orientin and vicenin are considered to be the major active components responsible for radioprotective function. These two components may increase the survival rate of mice when administered $30 \mathrm{~min}$ before whole-body exposure to $\gamma$-radiation (82). The two flavonoids may also reduce radiation-induced lipid peroxidation through their activities to scavenge free radicals in the liver and protect against chromosomal aberrations and stem cell death in bone marrow $(83,84)$.

Panax ginseng. P. ginseng is a well-known medicinal herb containing multiple bioactive constituents that is extensively used in China and Korea. The plant has a variety of beneficial activities including antitumor, antioxidant, anti-aging, antifungal, anti-inflammatory and neuroprotective properties (85-90). Ginseng contains various types of ginsenosides (major active components), kaempferol, caffeic acids, acidic polysaccharides and palmitic acids in its stem, leaves and roots. The majority of the evidence for the radioprotective properties of ginseng has been accumulated over the last 
several decades (90-93). For example, the administration of ginseng extracts resulted in suppression of radiation-induced inflammatory response through inhibition of cyclooxygenase- 2 overexpression, as well as recovery of spleen and thymus damage induced by radiation exposure in mouse models (94). In addition, whole ginseng extracts increased colony-forming capability and reduced apoptotic cell death in the spleen and intestine of irradiated mice (95). Another study reported that the protective effects of ginsan, an acidic polysaccharide of ginseng, led to enhanced cell proliferation of bone marrow and spleen, and increased production and release of hematopoietic grow th factors and various cytokines, including IL-1, IL-2, IL-4, IL-6, IL-12, interferon- $\gamma$ and TNF- $\alpha$, in irradiated mice (90). These cytokines may be necessary for recovery of the hematopoietic system and induction of the immune system to protect against radiation exposure. Furthermore, oral administration of ginseng root extracts to albino mice prior to whole-body exposure to $\gamma$-radiation increased survival rates and life expectancy, restored the levels of a number of endogenous antioxidants, including GST, CAT and SOD-1, and inhibited radiation-induced sickness and weight loss (92). These extracts also significantly decreased the increased level of radiation-mediated lipid peroxidation $(92,96)$.

Syzygium cumini. S. cumini, known as jamun, is used in traditional Indian systems of medicine. The bark, leaves, seeds and fruits of S. cumini are used for medicinal applications to treat diabetes, splenopathy, bacterial infection, constipation, stomachache, fever, gastropathy and dermopathy (97,98). This plant has been reported to contain flavonoids and phenolic acids, including ellagic acid, quercetin, kaempferol and myricetin. The bioactive constituents of the plant have various biological functions including antioxidant, anti-inflammatory, antibacterial, antidiabetic and cardioprotective properties $(99,100)$. A number of previous studies demonstrated the radioprotective role of $S$. cumini in the in vitro and in vivo systems (101-104). Administration of S. cumini leaf extracts resulted in suppression of radiation-induced micronuclei formation and protection of lymphocytes against DNA damage (102). Extracts of S. cumini leaves and seeds also exhibited radioprotective effects to lessen radiation-mediated sickness and mortality in mouse models $(100,103)$. Another previous study demonstrated that gastrointestinal damage, including a decrease in villus height and the number of crypts, and an increase in goblet and apoptotic cell numbers, was induced by exposure of whole-body g-radiation to mice, and this damage was prevented and reversed by pre-treatment with leaf extracts of S. cumini (105). In addition, the S. cumini extracts have ROS-scavenging activities as do other medicinal herbs. Results from a further study demonstrated that administration of the leaf extracts decreased the formation of free radicals, including hydroxyl radicals and superoxide anion radicals, leading to the suppression of radiation-induced lipid peroxidation and DNA damage in the brain and spleens of mice (106).

Zingiber officinale. Z. officinale, commonly known as ginger, is consumed extensively as a spice and flavoring herb worldwide. The rhizomes of ginger have been used for medicinal purposes in traditional Ayurvedic medicines to treat dyspepsia, asthma, cough, diarrhea, cardiac disorders, nausea, vomiting and inflammation (107-109). Ginger, or its extracts, contains limonene, cymene, cineole, zingiberene, terpenoid, geraniol, shogaol and gingerol, among other constituents, which demonstrate diverse pharmacological properties including analgesic, anti-inflammatory, antitumor and antioxidant activities (110-112). Previous studies have attested to the radioprotective potential of ginger $(113,114)$. One study demonstrated that the extracts of $Z$. officinale administered to mice with $\gamma$-radiation exposure enhanced the spleen weight, splenocyte proliferation, humoral immunity and secretion of cytokines including IL-1 $\beta$ and IL-3 in the spleens of mice, indicating alleviation of radiation-induced immunosuppression (113). In addition, hydroalcoholic extracts of ginger rhizomes have been reported to decrease lipid peroxidation and recover GSH levels through their free-radical-scavenging activities in irradiated mice $(114,115)$. The administration of ginger rhizome extracts prior to 2 Gy $\gamma$-radiation in rats also resulted in inhibition of lipid peroxidation and ascorbate ion stress via increased scavenging ability for ROS removal, which contributed to neurobehavioral protective effects against radiation-induced CTA (116,117).

\section{Conclusions}

It is clear that a number of TOMs exhibit a variety of biological activities with respect to radioprotective roles. However, only a limited number of TOMs have been studied, and clinical trials of the majority of TOMs have not yet been conducted. Although these medicinal plants have been utilized in numerous Asian countries, validation of their quality, chemical contents and underlying molecular mechanism of action is imperative prior to initiating clinical trials for application to current therapeutic systems. Indiscreet variations composed of similar agents have appeared due to a lack of regulation of these plant products. As environmental factors including soil content, water, temperature and acidity differ, different specimens of the same plant species frequently have differential amounts of the bioactive ingredients, leading to inconsistent outcomes of biological activities. Further studies are required to identify the bioactive constituents in TOMs responsible for specific properties including radioprotection. For preclinical assays and clinical application, it is important that the exact formula of TOMs or their active constituents be determined with specified preparation methods and that they be tested with strict validation and verification in accordance with modern scientific standards. Overall, further intensive studies of these medicinal plants are necessary to verify their potential for use as radioprotectors and application in further clinical trials.

\section{References}

1. Ahmad SS, Duke S, Jena R, Williams MV and Burnet NG: Advances in radiotherapy. BMJ 345: e7765, 2012.

2. Schaue D and McBride WH: Opportunities and challenges of radiotherapy for treating cancer. Nat Rev Clin Oncol 12: 527-540, 2015

3. Baskar R, Lee KA, Yeo R and Yeoh KW: Cancer and radiation therapy: Current advances and future directions. Int J Med Sci 9: 193-199, 2012. 
4. Copp RR, Peebles DD, Soref CM and Fahl WE: Radioprotective efficacy and toxicity of a new family of aminothiol analogs. Int J Radiat Biol 89: 485-492, 2013.

5. Kim W, Youn H, Kwon T, Kang J, Kim E, Son B, Yang HJ, Jung Y and Youn B: PIM1 kinase inhibitors induce radiosensitization in non-small cell lung cancer cells. Pharmacol Res 70: 90-101, 2013.

6. Kang J, Kim E, Kim W, Seong KM, Youn H, Kim JW, Kim J and Youn B: Rhamnetin and cirsiliol induce radiosensitization and inhibition of epithelial-mesenchymal transition (EMT) by miR-34a-mediated suppression of Notch-1 expression in non-small cell lung cancer cell lines. J Biol Chem 288: 27343-27357, 2013

7. Trotti A, Bellm LA, Epstein JB, Frame D, Fuchs HJ, Gwede CK, Komaroff E, Nalysnyk L and Zilberberg MD: Mucositis incidence, severity and associated outcomes in patients with head and neck cancer receiving radiotherapy with or without chemotherapy: A systematic literature review. Radiother Oncol 66: 253-262, 2003.

8. Furby A, Behin A, Lefaucheur JP, Beauvais K, Marcorelles P, Mussini JM, Bassez G, Créange A, Eymard B and Pénisson-Besnier I: Late-onset cervicoscapular muscle atrophy and weakness after radiotherapy for Hodgkin disease: A case series. J Neurol Neurosurg Psychiatry 81: 101-104, 2010.

9. Radvansky LJ, Pace MB and Siddiqui A: Prevention and management of radiation-induced dermatitis, mucositis, and xerostomia. Am J Health Syst Pharm 70: 1025-1032, 2013.

10. Chen Y and Okunieff P: Radiation and third-generation chemotherapy. Hematol Oncol Clin North Am 18: 55-80, 2004.

11. Prouillac C, Vicendo P, Garrigues JC, Poteau R and Rima G: Evaluation of new thiadiazoles and benzothiazoles as potential radioprotectors: Free radical scavenging activity in vitro and theoretical studies (QSAR, DFT). Free Radic Biol Med 46 1139-1148, 2009.

12. Kim W, Seong KM and Youn B: Phenylpropanoids in radioregulation: Double edged sword. Exp Mol Med 43: 323-333, 2011.

13. Yang HJ, Youn H, Seong KM, Yun YJ, Kim W, Kim YH, Lee JY, Kim CS, Jin YW and Youn B: Psoralidin, a dual inhibitor of COX-2 and 5-LOX, regulates ionizing radiation (IR)-induced pulmonary inflammation. Biochem Pharmacol 82: 524-534, 2011.

14. Brizel DM, Wasserman TH, Henke M, Strnad V, Rudat V, Monnier A, Eschwege F, Zhang J, Russell L, Oster W and Sauer R: Phase III randomized trial of amifostine as a radioprotector in head and neck cancer. J Clin Oncol 18: 3339-3345, 2000.

15. Hensley ML, Schuchter LM, Lindley C, Meropol NJ, Cohen GI, Broder G, Gradishar WJ, Green DM, Langdon RJ Jr, Mitchell RB, et al: American society of clinical oncology clinical practice guidelines for the use of chemotherapy and radiotherapy protectants. J Clin Oncol 17: 3333-3355, 1999.

16. Arora R, Gupta D, Chawla R, Sagar R, Sharma A, Kumar R, Prasad J, Singh S, Samanta N and Sharma RK: Radioprotection by plant products: Present status and future prospects. Phytother Res 19: 1-22, 2005

17. Weiss JF and Landauer MR: Protection against ionizing radiation by antioxidant nutrients and phytochemicals Toxicology 189: 1-20, 2003.

18. Jagetia GC: Radioprotective potential of plants and herbs against the effects of ionizing radiation. J Clin Biochem Nutr 40: 74-81, 2007.

19. Sagar SM: Can the therapeutic gain of radiotherapy be increased by concurrent administration of Asian botanicals? Integr Cancer Ther 9: 5-13, 2010.

20. Kma L: Plant extracts and plant-derived compounds: Promising players in a countermeasure strategy against radiological exposure. Asian Pac J Cancer Prev 15: 2405-2425, 2014

21. NambiarD, Rajamani P and Singh RP: Effects of phytochemicals on ionization radiation-mediated carcinogenesis and cancer therapy. Mutat Res 728: 139-157, 2011.

22. Bourgier C, Levy A, Vozenin MC and Deutsch E: Pharmacological strategies to spare normal tissues from radiation damage: Useless or overlooked therapeutics? Cancer Metastasis Rev 31: 699-712, 2012.

23. Maurya DK, Devasagayam TP and Nair CK: Some novel approaches for radioprotection and the beneficial effect of natural products. Indian J Exp Biol 44: 93-114, 2006.

24. Kuntic VS, Stanković MB, Vujic ZB, Brborić JS and Uskoković-Marković SM: Radioprotectors-the evergreen topic. Chem Biodivers 10: 1791-1803, 2013
25. Valerie K, Yacoub A, Hagan MP, Curiel DT, Fisher PB, Grant S and Dent P: Radiation-induced cell signaling: Inside-out and outside-in. Mol Cancer Ther 6: 789-801, 2007.

26. Multhoff $\mathrm{G}$ and Radons $\mathrm{J}$ : Radiation, inflammation, and immune responses in cancer. Front Oncol 2: 58, 2012.

27. Verheij M: Clinical biomarkers and imaging for radiotherapy-induced cell death. Cancer Metastasis Rev 27: 471-480, 2008

28. Fogg VC, Lanning NJ and Mackeigan JP: Mitochondria in cancer: At the crossroads of life and death. Chin J Cancer 30: 526-539, 2011.

29. Robbins ME and Zhao W: Chronic oxidative stress and radiationinduced late normal tissue injury: A review. Int J Radiat Biol 80: 251-259, 2004

30. Paun A, Kunwar A and Haston CK: Acute adaptive immune response correlates with late radiation-induced pulmonary fibrosis in mice. Radiat Oncol 10: 45, 2015.

31. Giridhar P, Mallick S, Rath GK and Julka PK: Radiation induced lung injury: Prediction, assessment and management. Asian Pac J Cancer Prev 16: 2613-2617, 2015.

32. Kim HU, Ryu JY, Lee JO and Lee SY: A systems approach to traditional oriental medicine. Nat Biotechnol 33: 264-268, 2015.

33. Cheung F: TCM: Made in China. Nature 480: S82-S83, 2011.

34. Kumar H, Song SY, More SV, Kang SM, Kim BW, Kim IS and Choi DK: Traditional Korean East Asian medicines and herbal formulations for cognitive impairment. Molecules 18: 14670-14693, 2013

35. Xu Z: Modernization: One step at a time. Nature 480: S90-S92, 2011.

36. Schmidt BM, Ribnicky DM, Lipsky PE and Raskin I: Revisiting the ancient concept of botanical therapeutics. Nat Chem Biol 3: 360-366, 2007.

37. Barabasi AL, Gulbahce N and Loscalzo J: Network medicine: A network-based approach to human disease. Nat Rev Genet 12: $56-68,2011$

38. Cao W, Li XQ, Wang X, Li T, Chen X, Liu SB and Mei QB: Characterizations and anti-tumor activities of three acidic polysaccharides from Angelica sinensis (Oliv.) Diels. Int J Biol Macromol 46: 115-122, 2010.

39. Yang X, Zhao Y, Zhou Y, Lv Y, Mao J and Zhao P: Component and antioxidant properties of polysaccharide fractions isolated from Angelica sinensis (OLIV.) DIELS. Biol Pharm Bull 30: 1884-1890, 2007.

40. Chen Y, Duan JA, Qian D, Guo J, Song B and Yang M: Assessment and comparison of immunoregulatory activity of four hydrosoluble fractions of Angelica sinensis in vitro on the peritoneal macrophages in ICR mice. Int Immunopharmacol 10: 422-430, 2010.

41. Xie CH, Zhang MS, Zhou YF, Han G, Cao Z, Zhou FX, Zhang G, Luo ZG, Wu JP, Liu H, et al: Chinese medicine Angelica sinensis suppresses radiation-induced expression of TNF-alpha and TGF-beta1 in mice. Oncol Rep 15: 1429-1436, 2006

42. Han G, Zhou YF, Zhang MS, Cao Z, Xie CH, Zhou FX, Peng $M$ and Zhang WJ: Angelica sinensis down-regulates hydroxyproline and Tgfb1 and provides protection in mice with radiation-induced pulmonary fibrosis. Radiat Res 165: 546-552, 2006.

43. Zhao L, Wang Y, Shen HL, Shen XD, Nie Y, Wang Y, Han T, Yin $M$ and Zhang QY: Structural characterization and radioprotection of bone marrow hematopoiesis of two novel polysaccharides from the root of Angelica sinensis (Oliv.) Diels. Fitoterapia 83: 1712-1720, 2012.

44. Lee JG, Hsieh WT, Chen SU and Chiang BH: Hematopoietic and myeloprotective activities of an acidic Angelica sinensis polysaccharide on human CD34+ stem cells. J Ethnopharmacol 139: 739-745, 2012

45. Liu C, Li J, Meng FY, Liang SX, Deng R, Li CK, Pong NH, Lau CP, Cheng SW, Ye JY, et al: Polysaccharides from the root of Angelica sinensis promotes hematopoiesis and thrombopoiesis through the PI3K/AKT pathway. BMC Complement Altern Med 10: 79, 2010

46. Chen XP, Li W, Xiao XF, Zhang LL and Liu CX: Phytochemical and pharmacological studies on Radix Angelica sinensis. Chin J Nat Med 11: 577-587, 2013.

47. Anand P, Thomas SG, Kunnumakkara AB, Sundaram C, Harikumar KB, Sung B, Tharakan ST, Misra K, Priyadarsini IK, Rajasekharan KN and Aggarwal BB: Biological activities of curcumin and its analogues (Congeners) made by man and Mother Nature. Biochem Pharmacol 76: 1590-1611, 2008. 
48. Hatcher H, Planalp R, Cho J, Torti FM and Torti SV: Curcumin: From ancient medicine to current clinical trials. Cell Mol Life Sci 65: 1631-1652, 2008.

49. Nemavarkar P, Chourasia BK and Pasupathy K: Evaluation of radioprotective action of compounds using Saccharomyces cerevisiae. J Environ Pathol Toxicol Oncol 23: 145-151, 2004.

50. Pal A and Pal AK: Radioprotection of turmeric extracts in bacterial system. Acta Biol Hung 56: 333-343, 2005.

51. Jagetia GC: Radioprotection and radiosensitization by curcumin. Adv Exp Med Biol 595: 301-320, 2007.

52. Nada AS, Hawas AM, Amin Nel D, Elnashar MM and Abd Elmageed ZY: Radioprotective effect of Curcuma longa extract on gamma-irradiation-induced oxidative stress in rats. Can J Physiol Pharmacol 90: 415-423, 2012.

53. Aravindan N, Madhusoodhanan R, Ahmad S, Johnson D and Herman TS: Curcumin inhibits NFkappaB mediated radioprotection and modulate apoptosis related genes in human neuroblastoma cells. Cancer Biol Ther 7: 569-576, 2008.

54. Qian Y, Ma J, Guo X, Sun J, Yu Y, Cao B, Zhang L, Ding X, Huang J and Shao JF: Curcumin enhances the radiosensitivity of U87 cells by inducing DUSP-2 up-regulation. Cell Physiol Biochem 35: 1381-1393, 2015.

55. Goel A and Aggarwal BB: Curcumin, the golden spice from Indian saffron, is a chemosensitizer and radiosensitizer for tumors and chemoprotector and radioprotector for normal organs. Nutr Cancer 62: 919-930, 2010.

56. Srinivasan M, Rajendra Prasad N and Menon VP: Protective effect of curcumin on gamma-radiation induced DNA damage and lipid peroxidation in cultured human lymphocytes. Mutat Res 611: 96-103, 2006.

57. Inano $\mathrm{H}$ and Onoda $\mathrm{M}$ : Radioprotective action of curcumin extracted from Curcuma longa LINN: Inhibitory effect on formation of urinary 8-hydroxy-2'-deoxyguanosine, tumorigenesis, but not mortality, induced by gamma-ray irradiation. Int $\mathrm{J}$ Radiat Oncol Biol Phys 53: 735-743, 2002.

58. Lee JC, Kinniry PA, Arguiri E, Serota M, Kanterakis S, Chatterjee S, Solomides CC, Javvadi P, Koumenis C, Cengel KA and Christofidou-Solomidou M: Dietary curcumin increases antioxidant defenses in lung, ameliorates radiation-induced pulmonary fibrosis, and improves survival in mice. Radiat Res 173: 590-601, 2010.

59. Jelveh S, Kaspler P, Bhogal N, Mahmood J, Lindsay PE, Okunieff P, Doctrow SR, Bristow RG and Hill RP: Investigations of antioxidant-mediated protection and mitigation of radiation-induced DNA damage and lipid peroxidation in murine skin. Int J Radiat Biol 89: 618-627, 2013.

60. Chan PC, Xia Q and Fu PP: Ginkgo biloba leave extract: Biological, medicinal, and toxicological effects. J Environ Sci Health C Environ Carcinog Ecotoxicol Rev 25: 211-244, 2007.

61. Jacobs BP and Browner WS: Ginkgo biloba: A living fossil. Am J Med 108: 341-342, 2000

62. Yirmibesoglu E, Karahacioglu E, Kilic D, Lortlar N, Akbulut G and Omeroglu S: The protective effects of Ginkgo biloba extract (EGb-761) on radiation-induced dermatitis: An experimental study. Clin Exp Dermatol 37: 387-394, 2012.

63. Sener G, Kabasakal L, Atasoy BM, Erzik C, Velioğlu-Oğünc A, Cetinel S, Gedik N and Yeğen BC: Ginkgo biloba extract protects against ionizing radiation-induced oxidative organ damage in rats. Pharmacol Res 53: 241-252, 2006.

64. Attia A, Rapp SR, Case LD, D'Agostino R, Lesser G Naughton M, McMullen K, Rosdhal R and Shaw EG: Phase II study of Ginkgo biloba in irradiated brain tumor patients: Effect on cognitive function, quality of life, and mood. J Neurooncol 109: 357-363, 2012.

65. Suleyman H, Gumustekin K, Taysi S, Keles S, Oztasan N, Aktas O, Altinkaynak K, Timur H, Akcay F, Akar S, et al: Beneficial effects of Hippophae rhamnoides L. on nicotine induced oxidative stress in rat blood compared with vitamin $\mathrm{E}$. Biol Pharm Bull 25: 1133-1136, 2002.

66. Cheng J, Kondo K, Suzuki Y, Ikeda Y, Meng X and Umemura K: Inhibitory effects of total flavones of Hippophae rhamnoides L on thrombosis in mouse femoral artery and in vitro platelet aggregation. Life Sci 72: 2263-2271, 2003.

67. Zeb A: Important therapeutic uses of sea buckthorn (Hippophae) A Review. J Biol Sci 4: 687-693, 2004

68. Goel HC, Prasad J, Singh S, Sagar RK, Kumar IP and Sinha AK Radioprotection by a herbal preparation of Hippophae rhamnoides, $\mathrm{RH}-3$, against whole body lethal irradiation in mice. Phytomedicine 9: 15-25, 2002.
69. Agrawala PK and Adhikari JS: Modulation of radiation-induced cytotoxicity in U 87 cells by RH-3 (a preparation of Hippophae rhamnoides). Indian J Med Res 130: 542-549, 2009

70. Gupta V, Bala M, Prasad J, Singh S and Gupta M: Leaves of Hippophae rhamnoides prevent taste aversion in gamma-irradiated rats. J Diet Suppl 8: 355-368, 2011

71. Shukla SK, Chaudhary P, Kumar IP, Samanta N, Afrin F, Gupta ML, Sharma UK, Sinha AK, Sharma YK and Sharma RK: Protection from radiation-induced mitochondrial and genomic DNA damage by an extract of Hippophae rhamnoides. Environ Mol Mutagen 47: 647-656, 2006.

72. Sureshbabu AV, Barik TK, Namita I and Prem Kumar I: Radioprotective properties of Hippophae rhamnoides (sea buckthorn) extract in vitro. Int J Health Sci (Qassim) 2: 45-62, 2008.

73. Goel HC, Kumar IP, Samanta N and Rana SV: Induction of DNA-protein cross-links by Hippophae rhamnoides: Implications in radioprotection and cytotoxicity. Mol Cell Biochem 245: 57-67, 2003.

74. Kumar IP, Namita S and Goel HC: Modulation of chromatin organization by RH-3, a preparation of Hippophae rhamnoides, a possible role in radioprotection. Mol Cell Biochem 238: 1-9, 2002

75. Rai MK: In vitro evaluation of medicinal plant extracts against Pestalotiopsis mangiferae. Hindustan Antibiot Bull 38: 53-56, 1996

76. Gupta SK, Prakash J and Srivastava S: Validation of traditional claim of Tulsi, Ocimum sanctum Linn. as a medicinal plant. Indian J Exp Biol 40: 765-773, 2002

77. Singh S, Majumdar DK and Rehan HM: Evaluation of anti-inflammatory potential of fixed oil of Ocimum sanctum (Holybasil) and its possible mechanism of action. J Ethnopharmacol 54: 19-26, 1996.

78. Devi PU: Radioprotective, anticarcinogenic and antioxidant properties of the Indian holy basil, Ocimum sanctum (Tulasi). Indian J Exp Biol 39: 185-190, 2001.

79. Uma Devi P and Ganasoundari A: Radioprotective effect of leaf extract of Indian medicinal plant Ocimum sanctum. Indian J Exp Biol 33: 205-208, 1995.

80. Monga J, Sharma M, Tailor N and Ganesh N: Antimelanoma and radioprotective activity of alcoholic aqueous extract of different species of Ocimum in C(57)BL mice. Pharm Biol 49: 428-436, 2011.

81. Subramanian M, Chintalwar GJ and Chattopadhyay S: Antioxidant and radioprotective properties of an Ocimum sanctum polysaccharide. Redox Rep 10: 257-264, 2005.

82. Uma Devi P, Ganasoundari A, Rao BS and Srinivasan KK: In vivo radioprotection by ocimum flavonoids: Survival of mice. Radiat Res 151: 74-78, 1999

83. Uma Devi P, Ganasoundari A, Vrinda B, Srinivasan KK and Unnikrishnan MK: Radiation protection by the ocimum flavonoids orientin and vicenin: Mechanisms of action. Radiat Res 154: 455-460, 2000

84. Nayak V and Devi PU: Protection of mouse bone marrow against radiation-induced chromosome damage and stem cell death by the ocimum flavonoids orientin and vicenin. Radiat Res 163: 165-171, 2005.

85. Shin JY, Song JY, Yun YS, Yang HO, Rhee DK and Pyo S: Immunostimulating effects of acidic polysaccharides extract of Panax ginseng on macrophage function. Immunopharmacol Immunotoxicol 24: 469-482, 2002.

86. Konoshima T, Takasaki M and Tokuda H: Anti-carcinogenic activity of the roots of Panax notoginseng. II. Biol Pharm Bull 22: 1150-1152, 1999.

87. Jung CH, Seog HM, Choi IW, Choi HD and Cho HY: Effects of wild ginseng (Panax ginseng C.A. Meyer) leaves on lipid peroxidation levels and antioxidant enzyme activities in streptozotocin diabetic rats. J Ethnopharmacol 98: 245-250, 2005.

88. Lee YS, Chung IS, Lee IR, Kim KH, Hong WS and Yun YS Activation of multiple effector pathways of immune system by the antineoplastic immunostimulator acidic polysaccharide ginsan isolated from Panax ginseng. Anticancer Res 17: 323-331, 1997.

89. Wang W, Shen H, Xie JJ, Ling J and Lu H: Neuroprotective effect of ginseng against spinal cord injury induced oxidative stress and inflammatory responses. Int J Clin Exp Med 8: 3514-3521, 2015.

90. Song JY, Han SK, Bae KG, Lim DS, Son SJ, Jung IS, Yi SY and Yun YS: Radioprotective effects of ginsan, an immunomodulator. Radiat Res 159: 768-774, 2003. 
91. Kim HJ, Kim MH, Byon YY, Park JW, Jee Y and Joo HG: Radioprotective effects of an acidic polysaccharide of Panax ginseng on bone marrow cells. J Vet Sci 8: 39-44, 2007.

92. Verma P, Jahan S, Kim TH and Goyal PK: Management of radiation injuries by panax ginseng extract. J Ginseng Res 35: 261-271, 2011

93. Bing SJ, Kim MJ, Ahn G, Im J, Kim DS, Ha D, Cho J, Kim A and Jee Y: Acidic polysaccharide of Panax ginseng regulates the mitochondria/caspase-dependent apoptotic pathway in radiation-induced damage to the jejunum in mice. Acta Histochem 116: 514-521, 2014.

94. Koo HJ, Jang SA, Yang KH, Kang SC, Namkoong S, Kim TH, Hang do TT and Sohn EH: Effects of red ginseng on the regulation of cyclooxygenase- 2 of spleen cells in whole-body gamma irradiated mice. Food Chem Toxicol 62: 839-846, 2013.

95. Kim SH, Son CH, Nah SY, Jo SK, Jang JS and Shin DH: Modification of radiation response in mice by Panax ginseng and diethyldithiocarbamate. In Vivo 15: 407-411, 2001.

96. Verma P, Sharma P, Parmar J, Sharma P, Agrawal A and Goyal PK: Amelioration of radiation-induced hematological and biochemical alterations in Swiss albino mice by Panax ginseng extract. Integr Cancer Ther 10: 77-84, 2011.

97. Arun R, Prakash MV, Abraham SK and Premkumar K: Role of Syzygium cumini seed extract in the chemoprevention of in vivo genomic damage and oxidative stress. J Ethnopharmacol 134: 329-333, 2011.

98. Muruganandan S, Srinivasan K, Chandra S, Tandan SK, Lal J and Raviprakash V: Anti-inflammatory activity of Syzygium cumini bark. Fitoterapia 72: 369-375, 2001.

99. De Bona KS, Bellé LP, Sari MH, Thomé G, Schetinger MR, Morsch VM, Boligon A, Athayde ML, Pigatto AS and Moretto MB: Syzygium cumini extract decrease adenosine deaminase, 5'nucleotidase activities and oxidative damage in platelets of diabetic patients. Cell Physiol Biochem 26: 729-738, 2010.

100.Jagetia GC, Baliga MS and Venkatesh P: Influence of seed extract of Syzygium Cumini (Jamun) on mice exposed to different doses of gamma-radiation. J Radiat Res 46: 59-65, 2005.

101. Srivastava $S$ and Chandra D: Pharmacological potentials of Syzygium cumini: A review. J Sci Food Agric 93: 2084-2093, 2013.

102. Jagetia GC and Baliga MS: Syzygium cumini (Jamun) reduces the radiation-induced DNA damage in the cultured human peripheral blood lymphocytes: A preliminary study. Toxicol Lett 132: 19-25, 2002.

103. Jagetia GC and Baliga MS: Evaluation of the radioprotective effect of the leaf extract of Syzygium cumini (Jamun) in mice exposed to a lethal dose of gamma-irradiation. Nahrung 47: 181-185, 2003

104. Baliga MS: Anticancer, chemopreventive and radioprotective potential of black plum (Eugenia jambolana lam.). Asian Pac J Cancer Prev 12: 3-15, 2011.
105. Jagetia GC, Shetty PC and Vidyasagar MS: Treatment of mice with leaf extract of jamun (Syzygium cumini Linn. Skeels) protects against the radiation induced damage in the intestinal mucosa of mice exposed to different doses of gamma-radiation. Pharmacology online 1: 169-195, 2008.

106. Jagetia GC, Shetty PC and Vidyasagar MS: Inhibition of radiation-induced DNA damage by jamun, Syzygium cumini, in the cultured splenocytes of mice exposed to different doses of $\gamma$-radiation. Integr Cancer Ther 11: 141-153, 2012.

107. Penna SC, Medeiros MV, Aimbire FS, Faria-Neto HC, Sertié JA and Lopes-Martins RA: Anti-inflammatory effect of the hydralcoholic extract of Zingiber officinale rhizomes on rat paw and skin edema. Phytomedicine 10: 381-385, 2003

108. Sharma SS and Gupta YK: Reversal of cisplatin-induced delay in gastric emptying in rats by ginger (Zingiber officinale). J Ethnopharmacol 62: 49-55, 1998 .

109. Young HY, Luo YL, Cheng HY, Hsieh WC, Liao JC and Peng WH: Analgesic and anti-inflammatory activities of [6]-gingerol. J Ethnopharmacol 96: 207-210, 2005.

110. Habib SH, Makpol S, Abdul Hamid NA, Das S, Ngah WZ and Yus of YA: Ginger extract (Zingiber officinale) has anti-cancer and anti-inflammatory effects on ethionine-induced hepatoma rats. Clinics (Sao Paulo) 63: 807-813, 2008

111. Ernst E and Pittler MH: Efficacy of ginger for nausea and vomiting: A systematic review of randomized clinical trials. $\mathrm{Br}$ J Anaesth 84: 367-371, 2000.

112. Lien HC, Sun WM, Chen YH, Kim H, Hasler W and Owyang C: Effects of ginger on motion sickness and gastric slow-wave dysrhythmias induced by circular vection. Am J Physiol Gastrointest Liver Physiol 284: G481-G489, 2003.

113. Du X, Pan H, Zhang C, Zhang H, Liu H, Chen Z and Zeng X: Zingiber officinale extract modulates $\gamma$-rays-induced immunosuppression in mice. J Med Plants Res 4: 1647-1655, 2010.

114. Jagetia GC, Baliga MS, Venkatesh P and Ulloor JN: Influence of ginger rhizome (Zingiber officinale Rosc) on survival, glutathione and lipid peroxidation in mice after whole-body exposure to gamma radiation. Radiat Res 160: 584-592, 2003.

115. Jagetia GC, Baliga M and Venkatesh P: Ginger (Zingiber officinale Rosc.), a dietary supplement, protects mice against radiation-induced lethality: Mechanism of action. Cancer Biother Radiopharm 19: 422-435, 2004.

116. Sharma A, Haksar A, Chawla R, Kumar R, Arora R, Singh S, Prasad J, Islam F, Arora MP and Kumar Sharma R: Zingiber officinale Rosc. modulates gamma radiation-induced conditioned taste aversion. Pharmacol Biochem Behav 81: 864-870, 2005.

117. Haksar A, Sharma A, Chawla R, Kumar R, Arora R, Singh S, Prasad J, Gupta M, Tripathi RP, Arora MP, et al: Zingiber officinale exhibits behavioral radioprotection against radiation-induced CTA in a gender-specific manner. Pharmacol Biochem Behav 84: 179-188, 2006. 